\title{
'Playing God Because you Have to': Health Professionals' Narratives of Rationing Care in Humanitarian and Development Work
}

\author{
Christina Sinding* and Lisa Schwartz, McMaster University \\ Matthew Hunt, McMaster University and Université de Montréal \\ Lynda Redwood-Campbell and Laurie Elit, McMaster University \\ Jennifer Ranford, Juravinski Cancer Centre, Hamilton
}

${ }^{*}$ Corresponding author: Christina Sinding, Associate Professor, School of Social Work and Department of Health, Aging \& Society, Kenneth Taylor Hall, Room
239, McMaster University, 1280 Main Street West, Hamilton, Ontario L8S 4M4, Canada. Tel: +905 525 9140; Fax: +905 525 4198; Email: sinding@mcmaster.ca.

This article explores the accounts of Canadian-trained health professionals working in humanitarian and development organizations who considered not treating a patient or group of patients because of resource limitations. In the narratives, not treating the patient(s) was sometimes understood as the right thing to do, and sometimes as wrong. In analyzing participants' narratives we draw attention to how medications and equipment are represented. In one type of narrative, medications and equipment are represented primarily as scarce resources; in another, they are represented as patient care. In the contexts respondents were working, medications and equipment were often both patient care interventions and scarce resources. The analytic point is that health professionals tend to emphasize one conceptualization over the other in coming to assert that not treating is right, or wrong. Rendering tacit ethical frameworks more explicit makes them available for reflection and debate.

Priority setting is a persistent challenge in health care. Much attention is devoted to assembling evidence and tools for planners charged with distributing limited resources across broad needs. Yet questions of who gets what, on what basis, necessarily implicate social values and social power (Kapiriri and Martin, 2007). Priority setting is especially consequential where medicines, equipment, health services and health professionals are scarce, as they often are in the global south (Wikler, 2003). Non-governmental aid organizations are significant players in health care provision in many low-income countries (Fuller, 2006) and fair allocation in humanitarian medicine raises ethical difficulties distinct from those encountered in other health care contexts (Hurst et al., 2009). Scholarly attention to the principles and practices of resource allocation in such organizations is however relatively rare.

Focusing on Médecins Sans Frontières (MSF) Holland, Fuller (2006) evaluated justifications for decisions to open, close, or substantially revamp a project (Fuller, 2006). Michael and Zwi (2002), exploring the ethical challenges that arose for the International Committee of the Red Cross (ICRC), discuss whether relief activities can legitimately focus on a narrow range of needs or a single component of health care. Both Michael and Zwi (2002) and Fuller (2006) offer important guidance for non-governmental organizations (NGOs) on the question of ethical resource allocation at the level of health care programs and policies. They do not focus primarily on the experiences of health professionals-the experiences of the people standing before the 'ocean of need' Michael and Zwi describe.

Various codes of practice articulate standards for humanitarian organizations and their workers. ${ }^{1}$ While statements of principle and values are helpful for illuminating the positions that should inform ethical decisions for workers, they are subject to the critique that besets principilism generally: the uncertainty that these are the best and only principles to guide ethically challenging decisions in health care (Clouser and Gert, 1990) and the lack of clarity about which of the principles should take precedence over the others when they appear in conflict, or how this should be determined. With respect to resource allocation for instance, the Code of Conduct for the International Red Cross and Red Crescent Movement and NGOs in Disaster Response Programmes (International Federation of Red Cross and Red Crescent Societies, 1994) indicates that aid is given 
'regardless of the race, creed or nationality of the recipients and without adverse distinction of any kind. Aid priorities are calculated on the basis of need alone...' This is a statement with which few would argue; however its application in situations where all needs cannot be met remains a challenge. For discussion and an example of how standards governing relief programs support relief efforts and might also undermine them, see Gostelow, 1999, Griekspoor and Collins, 2001.

Of the articles focusing on the narratives of health professionals engaged in humanitarian and international development initiatives, a few address priority setting in particular. In a MSF HIV/AIDS project in South Africa studied by Fox and Goemaere (2006), a lengthy list of medical, social and adherence criteria was developed to form the basis of patient selection. Clinical staff found decisions about who to start on antiretroviral treatment (and when) 'particularly difficult and disturbing.' In principle, patients were required to meet all of the criteria; in practice however patients were almost always admitted to the program, on the belief that they could be supported to meet the criteria.

Respondents in Hunt's (2008) study echoed Michael and Zwi's assessment of the magnitude of people's needs, and expressed dismay similar to that articulated by participants in Fox and Goemaere's (2006) study at the prospect of selecting which patients would receive health services. In contrast to the Fox and Goemaere study however, in the two specific patient selection scenarios described in Hunt (2008, p. 64), the decision not to treat was constructed as 'a right decision' in one and as at least potentially right in the other.

This article emerges from a project designed to understand ethical challenges faced by Canadian-trained health professionals while providing care in low-income countries in contexts of resource deprivation, armed conflict or disaster. More specifically the article elaborates the experiences and accounts of health professionals who have faced the dilemma of 'patient selection'. In exploring respondents' perceptions of their roles and responsibilities we are intent to make visible how decisions not to treat come to be understood as either right or wrong.

Various ethical theories have been applied to resource allocation. Daniels (2000) emphasize the essential aspects of fair process to ensure just distribution of scarce resources. Once morally justifiable process is in place, the substantive requirements of just distribution must be decided, moving from 'how' to 'what' decisions ought to be made (Persad et al., 2009). Global health ethics draws on authors such as Amartya Sen (2002) who makes the substantive claim that equity in health must attend to so- cial or political disparities which impact on availability of health related resources and interfere with full capability for human flourishing. Braveman and Gruskin (2003a, 2003b) assert that health equity is a human right, and Buchanan (Buchanan, 1995) argues that the benefits and burdens ought to be shared equally.

The narratives of participants in our study did reflect some of these theories. In the next phase of our research we will deliberately set formal ethical principals alongside respondents' narratives. In this paper, however, we proceed inductively, attempting to develop grounded theory that maps how study participants came to understand a particular action as right or wrong.

\section{Methods}

\section{Recruitment and Sample of Respondents}

We sought to interview health professionals in a range of disciplines who had delivered care as part of humanitarian or development organizations, and who had received their professional training in Canada. Information about the study was distributed through investigator contacts and through listservs and websites of humanitarian and development organizations (in some cases these organizations e-mailed an invitation to participate to all health professionals associated with the organization). From there, snowball sampling drew forward additional participants. Twenty people participated in the study, nine recruited from organizations, five through investigator contacts, and each of five participants recommended one other (one recommended two). Collectively respondents had worked with 20 different organizations in 37 countries and had participated in an average of four projects. Ten nurses, seven physicians and three allied professionals participated.

\section{Interviews and Thematic Analysis}

In semi-structured interviews respondents were asked to elaborate two or three situations that they found ethically difficult-to say what happened, who was involved, how they responded, what they took into account in responding. Each of the interviews was audiotaped and transcribed, and transcripts were independently reviewed by two members of the research team to identify the ethical dilemmas. Challenges emerging from four broad areas were identified in analysis: resource scarcity; aid agency policies and agendas; norms around health professionals' roles and interactions; histories and social structures (Schwartz et al, submitted). 


\section{Sample and Analysis for This Paper}

In this paper we draw on a sub-set of the accounts of resource scarcity dilemmas, those in which the respondent considered not treating a patient (or group of patients) because of resource limitations-constraints on the medication, equipment or staff available either in that moment or over the time required. We included in our analysis only those situations in which the respondent perceived she or he could have provided or arranged for treatment in that setting. We thus for instance excluded one respondents' story about a woman with a broken hip who did not receive surgery because, as he said, 'there was no possibility of treatment... where I was working... the treatment was not available,' and a similar case in which a child was not treated for cancer.

In total we identified thirteen narratives of this type, offered by nine respondents (five physicians, four nurses). We drew on grounded theory methods to analyze respondents' accounts. Grounded theory methods aim to generate a conceptual rendering of the main concerns of those resolving a particular problem (Glaser, 2002). In open coding questions such as: what is happening here? what is the main concern faced by participants? what accounts for the resolving of this concern? (Glaser, 2004) were 'answered' with codes, or concepts. Each coded section of data was compared to others similarly coded, both to elaborate the respondents' concerns and their ways of working them through and to distinguish them from other sorts of concerns and responses. Reflections about possible relationships between codes were captured in theoretical memos and allowed us to begin to formulate broader concepts, specify their properties, and refine them in dialogue with the data (Glaser, 2004).

\section{Results}

In all of the accounts discussed in this paper, health professionals considered not treating a patient or group of patients for reasons primarily related to resource limitations-constraints on the medication, equipment and staff they had available, either in that moment or over the time the resources were required. That consideration was given to not treating in all cases does not mean that treatment was never given, or that-more to the point of this paper-not treating was assigned the same moral valence. In the narratives, not treating the patient(s) was sometimes constructed as the right thing to do, and sometimes as wrong. We present first the scenarios in which not treating was assessed by the respondent as the right thing to do, and then the scenarios in which not treating was understood to be wrong.
Throughout, we draw attention to the following themes: how medications and equipment are represented; how the role of health professionals is understood; who and what is seen to be at risk in treating or not treating; and the perspective taken (patient/ family, organization).

\section{Not Treating as the Right Thing to Do}

R3 worked as a physician in a rural hospital in Northeast Africa that had one oxygen machine and often more than one patient needed it at a time. Moreover, the machine ran on a generator which could not be operated continuously. These limitations set up two sorts of dilemmas that other respondents also encountered: having to choose one patient over another, and having to choose between the needs of current patients and the (possibly more acute) needs of future patients:

So we have to make decisions if I am going to put the oxygen machine on patient A or patient $B$; and am I going to use it through the night which means the generator will have to be shut off for at least part of the time tomorrow. And someone may come in very sick and need the oxygen more....

R3 noted that age was occasionally a factor in decisions; at times when two patients could benefit, the child received the oxygen rather than the adult. In most instances however the choice revolved around whether or not this person's life could be saved by the oxygen at hand:

Certainly there are times where I felt the patient was going to die anyways and letting the oxygen go through the night and losing our generator for the next day was not the smart thing to do.

In his discussion of this scenario, R3 foregrounds a particular conceptualization of equipment and medications: as scarce resources. Here, having given oxygen to a patient who dies is understood not as having provided care, but rather as having wasted resources, acted unwisely.

In her narrative Respondent 19 (a nurse) also, and quite explicitly, constructed medication and equipment as scarce resources, resources that must not be wasted. In discussing how her team (at an urban hospital in the Caribbean) responded to premature babies she noted that 'sometimes for a real preemie they won't even admit them,' and explained that almost invariably in the case of very premature infants:

they'll treat with IV, they'll treat with NG [nasogastric feeds], they'll give oxygen, they'll give antibiotics, they'll give an electric heating blanket to keep it warm but even after all these invested resources they usually die. 
R19 reflected on how her perspective has changed, with repeated witnessing of this sort of situation. When she first worked in this part of the world she recalls having thought 'yes, yes we have to do everything we can'. Yet,

whenever you see so many sick kids and you realize that there are some that have to be turned away then you do say okay well we need to triage and we need to decide you know who we're going to treat and it seems to be a natural tendency to say let's treat the ones that we can save.

Eventually, she says, she came to endorse the philosophy she perceived the local staff to hold: 'if we're investing into children that we are certain will die, then we're taking away resources that could be allocated instead on a child that has a chance.'

In the scenario R3 described, not running the generator was viewed as a way of preserving treatment for future patients. Similarly for R19, treating children unlikely to live is 'taking away' resources from other children. This theme that not treating certain patients was ultimately in service of treating other patients-most commonly, patients more likely to live-recurred. These narratives raise the issue of treatment futility. The phrase 'the patient is going to die anyway' is invoked, of course, in health care contexts around the world. The phrase means that the patient will (likely) die even if all of the care resources available are brought to bear on her or his condition and needs. The difference between the two contexts is in the 'anyway,' in what resources can be brought to bear on the patients' needs:

I mean, here in Canada, we would intubate somebody and we would put them on a ventilator and then we've got an intensive care unit to take care of these people. There we don't have that. So if we resuscitate somebody it's basically we take the chance that ok if this works it works, if it doesn't, it doesn't. [R14]

Assessments of treatment futility, then, are contextual; we return to this point in the conclusion.

In R19's account we can also see that, as medication and equipment are increasingly perceived as 'invested resources,' the nature of health professionals' responsibilities shift. From treating all patients (doing 'everything we can'), emphasis shifts here to health professionals discerning who is likely to live and who is likely to die, and directing resources away from those likely to die and towards those likely to live. In this way, as with R3's narrative above, not treating avoids bad investments in favour of good ones. At the same time R19 described situations in which premature babies, not expected to live, did in fact survive. She and other respondents noted the diffi- culty of being certain that a particular intervention will not save a patient's life. Yet the importance of making such determinations was not necessarily undermined by this uncertainty:

You're playing God because you have to at some point because there are just too many, there's just too many sick cases and sick kids that you can't look after them all with the staffing usually, with the time and with the resources.

In addition to inadequacies in the resource at hand, the sustainability of resources over time and over the range of need was sometimes at issue. Four of the health professionals who participated in the study described encountering patients who almost certainly had HIV or TB, but for whom they did not provide treatment. R18 did not discuss the rightness or wrongness of not treating these patients. R19 and R2 said essentially that they understood the reasoning behind not treating, and could accept it:

We had one little girl that was dying from tuberculosis... we kept being told from headquarters again you need to go through the government tuberculosis program. So we would go to the city you know, fly to the city where we could meet with those officials and then you find out that they have no meds. They can't get out to where we are, its too isolated, it's too whatnot. Again we were saying to our headquarters, can't we just get some TB [medication] for these patients that we are seeing. In some ways I understand what they say too is the area, I mean I told you it was secure but I mean we still didn't know if we would be evacuated at some point.... I understand what [the agency] was saying, we can't treat we're not here long enough, we're not sure that we're here long enough, we need to work with the government, well those are valid points... [R19]

I knew the project was leaving after 6 months and we couldn't start it.... I could accept that you know there was a valid reason for not doing it... what that does to the HIV infection ... It increases drug resistance... [and] it wasn't like you know that we could take you know sort of draw a line in the sand and say we're going to have to treat because we can't. [Agency] can't... in the end that would be all they did because it could consume the whole organization, the whole resources everything. And so none of the other health problems would be you know addressed. So I can see it. [R2]

Factors beyond the immediate availability of resources were at play in these situations: TB and HIV medications require administering over time to be effective and to minimize the risks of drug resistance for individuals 
and communities. Some agencies deliberately do not provide treatment if doing so is seen to undermine local responses, or if the agency itself cannot be sure its presence can be sustained (for reasons of its own resource limitations, or if conflict breaks out, for example). At this broader level we also see this intent that appears in narratives of immediate patient care encounters, the intent to preserve resources for other patients.

While R2 and R19 both spoke of distress about not treating patients in these situations, particularly when patients had active symptoms, the reasons for not treating were described 'valid' — not fully right, perhaps, but also not wrong.

\section{Not Treating as Wrong}

Respondent 14, a nurse who managed a department and provided direct care at a remote hospital in east-central Africa, spoke about children with malaria and pneumonia who stopped breathing several times in the course of a day. Each time R14 made the decision to resuscitate a particular child, until 'I finally had to say... we're not going to continue doing this ... because they are going to die anyway.' R14 went on to discuss the family's questioning of her actions, and her terrible sense of responsibility for making this 'final, final' decision. As this sort of scenario recurred, she said, the team considered adopting a practice of not attempting to resuscitate children in this condition at all:

Amongst our team it was the decision ... should we be doing that at all then? Should we just let them die ... and not even bother? Well you want to do everything to make them live, right?... So yeah I mean I think so again it's a decision as a nurse you want to make and say, ok what can I do to help this child at this moment? So yeah I would go run for the ambu bag and start resuscitating.

In this particular account R14 constructs the decision not to treat as both irresponsible and uncaring: to 'not even bother' represents both an abdication of responsibility, and a kind of callousness. She also highlights her identity 'as a nurse', linking this identity with a desire to make certain sorts of decisions: to respond to 'this child at this moment' by running for the equipment, and starting to resuscitate.

Similar images appear in an account offered by R3. An outreach team brought a young woman in a coma to the hospital in rural northeast Africa where R3 was working. The young woman was a Type 1 diabetic, and began to recover as the medical team treated her with insulin. Yet when the team communicated their need for additional insulin to head office, they received the message that 'this was not someone that we could treat' (because in her village the woman would not be able to afford syringes or insulin, or have access to a fridge to store the insulin). R3 describes how the health team responded to this message:

I know myself and a lot of the staff, both the expat and the national staff had a real problem with this because she had already been in our hospital for three to four weeks. We had gotten to know her husband and her kids. It's a treatable disease. And we just found ourselves in this rather extreme situation... we were basically supposed to wash our hands of this and let her go home and die...

Here, as in the scenario R14 describes immediately above, not treating is constructed as a kind of abdication of responsibility, and an abandonment of the patient. Again as with R14, not treating is set as equivalent to letting the patient die. This is in contrast with the narratives above, where it is the withdrawal or denial of the resource that is emphasized (not admitting to hospital, not running the generator, not bagging the patient) rather than the patient dying.

Ultimately R3's team made a decision to treat the woman for a considerable length of time at the hospital, against explicit direction not to. In part using their personal funds they also bought syringes and insulin. As R3 said, 'everyone fortunately was on the same page, and we all felt that she deserved every chance she could ...' R3 went on to speak further about the woman's family. Her husband 'was very, very supportive and she had young kids and he seemed to be, relatively speaking, a man of some means...'; he found a fridge at a health outpost in another village and the family was willing to move there, and he brought money to show that he would be able to buy insulin and syringes if the health professionals could tell him where to purchase them. Here R3's narrative echoes R19's. Both describe 'exceptions' being made: decisions to treat were taken against instruction from elsewhere and in situations where the patient might well have 'died anyway.' In each case, a personal relationship between the professionals and the patient was cited as a significant factor in the decision, and the devotion of the patient's family was highlighted. Interestingly, R3 also draws forward a sustainability argument: while other families might not be able to afford or store the medication, this particular family could. The husband's devotion, combined with his resources, suggest a greater likelihood that the treatment plans will succeed. Here the principles of sustainability is relevant to the decision making, though it is clearly a 'negotiation' of the principle the organization held (Hilhorst and Schmiemann, 2002). 
Towards the end of this story, R3 considers how things may have unfolded for the family:

The reality may unfortunately be that a month later they were out of insulin and syringes and the outcome was the same and we used a lot of precious resources and time and energy into what maybe was rightfully identified as what was a hopeless case. But, I think I mean that was one of the most frustrating and ethically challenging things that I that I think I faced, was the idea of resource limitations and you make your choice when you now have the people in front of you... The reality is, is it may not be practical for [agency] to start treating Type I diabetics and perhaps there are good reasons why we shouldn't. But at that same time as an individual and as a well paid Canadian physician, I can buy her that insulin and syringes. I can keep her alive and again it is not practical for me to spend my own money, or collectively our money, on one situation because there are so many patients and we can't help them all.

Once again the considerable difficulty, indeed in some sense the impossibility, of a health professional not treating an ill person 'in front of you' is emphasized. Here and above, the patient right in front of you 'at this moment' is set against more distant, less immediate, considerations. The apparently practical, rational decisions about how to best use scarce resources are considerably less convincing in the time and place of the encounter with a real person in need. R3 also draws attention in this passage to his own positioning: while it may be reasonable for an agency to take a decision not to treat people with certain illnesses, his position as a physician, and as an individual with resources of his own, is brought to bear. The agency may be right to take a position against treating in this case, but that does not necessarily render it right for him personally in this situation not to treat this patient.

\section{Discussion}

\section{Not Treating as the Right, or the Wrong, Thing to Do}

While each respondent ultimately reached a conclusion (not treating is right, not treating is wrong) they commonly discussed both the rightness and wrongness of not treating in each situation they described. Indeed, in some narratives assertions about the rightness and wrongness of a decision appeared within the space of a sentence or two, reflecting the complexity, strain and messiness that often characterized participants' accounts (and that is somewhat obscured by the analysis below). Certainly a participant's conclusion that not treating was the right thing to do in a particular situation did not mean that this conclusion, or acting on it, was in any way easy. R2 made this explicit: 'there was a valid reason for not doing it [not treating people with HIV]. You know it didn't make me feel any better.'

With these caveats, we can offer reflection on the themes evident in respondents' narratives about decision making in situations of resource scarcity. These themes include: how medications and equipment are represented; how the roles of health professionals are understood; who and what is seen to be at risk; and the perspective taken (patient/ family, organization). Participants' different orientations to the themes help us understand how they came to their conclusions about the rightness or wrongness of not treating.

In the 'not treating is the right thing'-type narrative, medications and equipment are represented primarily as scarce resources. The instrumental value of medications and equipment is highlighted: they are 'for' keeping people alive. The professional's responsibility is to determine which patients, offered the resources at hand at that time, are likely to live, and which are likely to die even with full access to these resources. The use of medication and equipment is understood as an investment in a person's survival. The health professional is the administrator of resources, with the responsibility to make good investments (that is, to treat only those patients likely to live) and to avoid making bad investments (treating those likely to die, and /or offering treatment that cannot be sustained). In this framework, not treating preserves, and does not waste, scarce resources, and these resources are available to patients who are more likely to benefit from them. In addition, the 'not treating is the right thing'-type narrative highlights the potential risks of administering medications in situations where they cannot be sustained (increased drug resistance).

In the 'not treating is the wrong thing'-type narrative, medication and equipment are represented primarily as health care and health interventions, and use of them is understood to have both instrumental and symbolic value. The professional's responsibility is to respond to these patients, right here, right now. Offering treatment sometimes saves people's lives; it also confirms the health professional's identity as a health professional (and to some extent confirms the patient as worthy, deserving of care). The perspective of patients and families (particularly parents) is highlighted. Their suffering in combination with the professional's knowledge and resources renders not treating wrong. Not treating is equated with the abandonment of patients and families, the abdication 
of professional responsibility, and threatens personal and professional identity and integrity. ${ }^{2}$

The analysis presented in this paper confirms findings from Hunt (2008). In the scenario he describes in which not treating was assessed as the right thing the scarcity of resources was emphasized, along with the preservation of resources for patients more likely to survive: 'there are a lot of kids with pneumonia that need resources and if you give them the resources they will get better...' (Hunt, 2008, p. 64) In the scenario in which not treating was understood as wrong, the symbolic significance of the treatment, the meaning it held for the patient's family (and potentially for the staff) was highlighted: 'the grandmother left knowing that at least we tried to do something for her child and her grandchild' (Hunt, 2008, p. 64).

Our findings also have some parallels with those of Fox and Goemaere (2006). In discussing the care team's reluctance to refuse anyone ARV treatment, Fox and Goemaere note that the team believed that patients could be supported, both before and after treatment began, to meet the criteria. This reasoning echoes with that of R3, whose team chose to treat a diabetic patient who did not meet the formal organizational mandate on the belief that she and her family, given their personal characteristics and resources, could be supported to meet the core requirements of that mandate (that is, the intervention would be sustainable). Similarly, personal knowledge of and relationships with patients commonly contributed to the felt sense that not treating was wrong.

In more general terms however there is an apparent discord between the Fox and Goemaere (2006) study and ours. While respondents in their study chose extremely rarely to not admit patients to treatment, respondents in the current study reported many instances of not treating patients-and, far more often took the position that not treating was the right thing. We can speculate about why this difference exists. First, as Fox and Goemaere make clear, the key limitation at the project they studied was not medicine or equipment but staff. While an oxygen machine can simply not be made to produce more oxygen, a staff person may stretch to accommodate more patients. Along the same lines, while our participants were well aware that TB and HIV medication existed, they did not necessarily have it at hand when they were confronted with ill patients. Thus, the material resource limits many of our participants faced were not operating in the same way. As well, in that setting the 'contraindications' to treating (likelihood of poor patient adherence) was understood as negotiable (Giacomini et al., 2000); this was not often the case for the patients discussed by participants in our study.
In a paper written in response to Fox and Goemaere (2006), Benatar (2006, p. 326) suggests that a tendency to practice "rescue medicine' with no attempt spared... in the hope that death can be averted', while an understandable aspect of conventional medical practice, must be tempered with principles of public health ethics. Participants in our study, reflecting on decisions not to treat patients with AIDS and tuberculosis, appeared to foreground the risks of treating - the risk to individuals and communities of drug resistance-far more consistently than did participants in the Fox and Goemaere study. One might argue that our participants more fully engaged the principles of public health ethics. There is another possible explanation however. For the team Fox and Goemaere (2006) studied, the public health risks emerged from patients' difficulty adhering to treatment. For several participants in our study, the question of adherence lay with the professionals: health professionals and the medications they carried might abruptly leave. The possibility-indeed in some cases the likelihood-that the professionals would have to 'quit treatment,' rendered the public health risk of beginning treatment greater than that which prevails when individual patients do not persist with a treatment regimen. In this analysis, the difference between the two sets of responses relates to differences in the perceived level and nature of risk on the ground, and responsibility for that risk.

In examining justifications for resource allocation decisions taken by MSF Holland, Fuller (2006) considers the perspectives of various stakeholders. A few of the respondents in this study also linked the rightness or wrongness of decisions not to treat to the standpoints of the people involved in the decision. For the most part these accounts suggested that decisions were rendered more ethical when people in the setting, people 'on the ground' controlled them, though definitions of 'local' and 'the ground' varied (the entire health team (expatriate and local); the local health professionals; the local community leaders; patients and their families). Studies with health practitioners and policy makers in low-income countries add an additional layer to this issue. In a study by Kapiriri and colleagues (2007) in Uganda, donors (including health workers in humanitarian and development organizations) were considered to have more say than is ideal in resource allocation decisions. The authors also note that the preference of most survey respondents to treat the seriously ill (rather than treating the less-ill patient more cost effectively) is consistent with patterns in other countries, and call for debate over both the principles and players in priority setting to ensure legitimacy. 


\section{Conclusion}

In this paper we have highlighted themes in respondents' narratives that help us conceptualize how conclusions about the rightness or wrongness of not treating are drawn. In the 'not treating is the right thing'-type narrative, medications and equipment are represented primarily as scarce resources, and health professionals are administrators of those resources. In this framework not treating preserves, and does not waste, scarce resources, and these resources are available to patients who are more likely to benefit from them. In the 'not treating is the wrong thing'-type narrative, medication and equipment are represented primarily as health care and health interventions, and use of them is understood to have both instrumental and symbolic value. Not treating is equated with the abandonment of patients and families, the abdication of professional responsibility, and threatens personal and professional identity and integrity.

Again it is worth emphasizing the heuristic quality of this analysis. In the contexts respondents were working, medications and equipment were often both patient care interventions and scarce resources. The point for the purposes of analysis is that health professionals tend to emphasize one set of images and concepts over the other in coming to perceive and assert that not treating is right, or wrong. Methodologically, we can also make the point that storytelling itself is a moral project; in what we include and exclude from stories, in our emphases and minimizations, we also construct ourselves and our actions as worthy (Reissman, 2001).

This study has several limitations, some ordinary and others more significant. We draw on a relatively small number of accounts, so the narrative 'types' we describe must be understood as provisional, awaiting confirmation, expansion and correction in further study. We have paid minimal attention to the specificities of the very broad range of settings in which the health professionals were working, or the length of time they had spent providing care in these settings, or their particular roles-no doubt these factors shape the ways they consider decisions not to treat.

In terms of more significant limitations: as is apparent in the quotes we have offered, the phrase 'the patient is going to die anyway' was commonly associated with the argument not to treat. This phrase is invoked in health care contexts around the world to justify not treating. That this is true suggests a kind of similarity in decision making across contexts: if a patient is very likely to die, if treatment is futile, then continuing to treat is reasonably understood as wrong, anywhere in the world. What this refrain hides, however, is the profound difference in the 'anyway,' the profound differences in how futility is constituted. Treatment futility relates both to the available resources and to the condition of the patient when she arrives for care. Both are deeply contextual. R14's narrative makes this most clear. Her decisions about whether or not to resuscitate a patient were made based on the likelihood that the intervention the team could offer would save the life of the patient, and on the fitness of the patient; especially malnourished patients were not resuscitated. The ethical dilemma for study respondents arises when they perceive that futility is defined by the scarcity of the available resources rather than the patient's condition. If a patient has stopped breathing or her heart has stopped in Canada, treatment is futile if, even with intubation and a ventilator and the full resources of an intensive care unit, she will 'die anyway.' In the context where our participants worked, treatment for this same patient is futile if a hand-held bag mask valve unit is insufficient to restart her heart and breathing. So while at some level the decision not to treat a patient likely to die rests on similar arguments across contexts, the different levels of resources underpinning the threshold for futility render the substance of the decisions very different.

We make this point to make more visible realities that may not be especially apparent in the analysis above-and, in the process, to trouble our methodology. In discussing various ways to teach global health ethics, Dwyer (2003) makes a case for case studies: they capture attention, they make real problems apparent, and they allow for and require analysis. At the same time, he suggests, case studies 'sometimes take the social context as a given' (Dwyer, 2003, p. 442). Our approach in this paper is subject to a similar critique: in attending to specific care situations, we take as given the contexts of those situations. We offer an analysis of how health professionals understood and handled the conditions they faced, but we do not examine how those conditions came to be. We also fail to examine how respondents came to perceive the constraints on care they (and their patients) faced as insurmountable, or not. This latter point is perhaps most salient to the cases we excluded. We 'accepted' that hip surgery was simply not available because a respondent asserted that this was the case. Yet we know (as no doubt he did as well) that hip surgery is available somewhere in that country or a neighbouring country for a price, and that for a price people with broken hips can be flown to medical centres, and so on.

We do not pursue this issue further but rather make the following points. The analysis offered here allows us to better understand the values at play when health professionals consider not treating patients or groups of patients. Value frameworks have real consequences for who 
gets (and does not get) what, especially in conditions of significant resource constraint, and making implicit value frameworks explicit makes these frameworks available for reflection and debate (Giacomini et al., 2000). In terms more particular to this study, a second stage of investigation will set these study findings against normative frameworks for ethical decision making, with the intent of contributing to a more adequate and contextually relevant ethics framework for health professionals working in humanitarian and international development initiatives.

And although there are merits to more reflexive and more just 'patient selection,' neither the needs of patients nor the care resources available to respond to these needs should be taken as given. Constraints on care resources are not 'natural.' Scarcity emerges from global relations that benefit wealthy nations; scarcity is 'not the result of any absolute lack of a resource but rather of the decision by society that it is not prepared to forgo other goods and benefits in a number sufficient to remove the scarcity' (Schrecker, 2008, p. 600; see also Benatar, 2002, Farmer and Campos, 2004). The perceived necessity of 'playing God' emerges from very human histories, human social arrangements, and human choices.

\section{Notes}

1. Among these are the United Nations Draft Declaration on Bioethics and Human Rights (2005), UNDP's Disaster Management Ethics module through their Disaster Management Training Program (1997), the Sphere Project's Humanitarian Charter and Minimum Standards in Disaster Response (2000), the Code of Conduct for the International Red Cross and Red Crescent Movement and NGOs in Disaster Response Programmes (1994) and the World Medical Association Statement on Medical Ethics in the Event of Disasters (1994).

2. The analysis of participant accounts included a search for negative instances (cases where the participant's account contradicted the framework outlined here). In one case a participant spoke of the suffering of ill people and reflected explicitly on the perspective of the mother, calling his failure to treat her child 'inexcusable' from her vantage point. Yet, contrary to the pattern in other narratives with these features, this participant arrived at the position where not treating was the right thing to do. Notable in this case was how evocatively the participant went on to emphasize the risks of 'opening the door' by treating one patient: ill people would come from miles around, local health professionals would take a break, and the aid agency would be completely overwhelmed. Both 'types' of narratives, then, operated strongly in this participant's account. This is perhaps explained in part by the particular mandate the participant faced-rather than proscriptions against treating certain patients or conditions, this participant's remit was to treat only patients with TB.

\section{Acknowledgements}

Our appreciation is extended to the health professionals who agreed to be interviewed for this study, and to Patricia Miller, Lori Luther and anonymous reviewers for thoughtful comments on an earlier version of the paper.

\section{References}

Benatar, S. (2006). Facing Ethical Challenges in Rolling Out Antiretroviral Treatment in Resource-Poor Countries: Comment On 'They Call It 'Patient Selection', in Khayelitsha. Cambridge Quarterly of Healthcare Ethics, 15, 322-330.

Benatar, S. R. (2002). The HIV/AIDS Pandemic: A Sign of Instability in a Complex Global System. Journal of Medical Philosophy, 27, 163-177.

Braveman, P. and Gruskin, S. (2003a). Defining Equity in Health. Journal of Epidemiology and Community Health, 57.

Braveman, P. and Gruskin, S. (2003b). Poverty, Equity, Human Rights and Health. Bulletin of the World Health Organization, $\mathbf{8 1}$.

Buchanan, A. (1995). Privatization and Just Health Care. Bioethics 9220-9239.

Clouser, K. and Gert, B. (1990). A Critique of Principlism. Journal of Medical Philosophy, 15, 219-236.

Daniels, N. (2000). Accountability for Reasonableness: Establishing a Fair Process for Priority Setting is Easier than Agreeing on Principles. British Medical Journal, 321, 1300-1301.

Dwyer, J. (2003). Teaching Global Bioethics. Bioethics, 17, 432-446.

Farmer, P. and Campos, N. G. (2004). Rethinking Medical Ethics: A View from Below. Developing World Bioethics, 4, 17-41.

Fox, R. C. and Goemaere, E. (2006). They Call It 'Patient Selection' in Khayelitsha: The Experience of Medecins Sans Frontieres-South Africa in Enrolling Patients to Receive Antiretroviral Treatment for HIV/AIDS. Cambridge Quarterly of Healthcare Ethics, 15, 302-312.

Fuller, L. (2006). Justified Commitments? Considering Resource Allocation and Fairness in Medecins Sans Frontieres-Holland. Developing World Bioethics, 6, 5970. 
Giacomini, M. K., Cook, D. J., Streiner, D. L. and Anand, S. S. (2000). Using Practice Guidelines to Allocate Medical Technologies. An Ethics Framework. International Journal of Technology Assessment in Health Care, 16, 987-1002.

Glaser, B. (2002). Conceptualization: On Theory and Theorizing Using Grounded Theory. International Journal of Qualitative Methods, 1, Article 3. Available from www.ualberta.ca/ ijqm [accessed February 15, 2007].

Glaser, B. (2004). Remodeling Grounded Theory. Forum: Qualitative Social Research, 5.

Gostelow, L. (1999). The Sphere Project: The Implications of Making Humanitarian Principles and Codes Work. Disasters, 23, 316-325.

Griekspoor, A. and Collins, S. (2001). Raising Standards in Emergency Relief: How Useful are Sphere Minimum Standards for Humanitarian Assistance? British Medical Journal, 323, 740.

Hilhorst, D. and Schmiemann, N. (2002). Humanitarian Principles and Organizational Culture: Everyday Practice in Médecins Sans Frontières-Holland. Development in Practice, 12, 490-500.

Hunt, M. R. (2008). Ethics Beyond Borders: How Health Professionals Experience Ethics in Humanitarian Assistance and Development Work. Developing World Bioethics, 8, 59-69.

Hurst, S. A., Metzger, N. and Mauron, A. (2009). Allocating Resources in Humanitarian Medicine. Public Health Ethics, 2, 89-99.
International Federation of Red Cross and Red Crescent Societies. (1994). Code of Conduct for the International Red Cross and Red Crescent Movement and NGOs in Disaster Response Programmes.

Kapiriri, L. and Martin, D. K. (2007). A Strategy to Improve Priority Setting in Developing Countries. Health Care Analysis, 15, 159-67.

Michael, M. and Zwi, A. B. (2002). Oceans of Need in the Desert: Ethical Issues Identified While Researching Humanitarian Agency Response in Afghanistan. Developing World Bioethics, 2, 109-130.

Persad, G., Wertheimer, A. and Emanuel, E. J. (2009). Principles for Allocation of Scarce Medical Interventions. The Lancet, 373.

Reissman, C. (2001). Analysis of Personal Narratives. In Holstein, J. and Gubrium, J. (eds), Handbook of Interview Research. Thousand Oaks, CA, Sage.

Schrecker, T. (2008). Denaturalizing Scarcity: A Strategy of Enquiry for Public-Health Ethics. Bulletin of the World Health Organization, 86, 600-605.

Schwartz, L., Sinding, C., Hunt, M., Elit, L., RedwoodCampbell, L., Adelson, N., Luther, L., Ranford, J. and deLaat, S. (submitted 2010). Ethics in Humanitarian Aid Work: Learning from the Narratives of Humanitarian Health Workers.

Sen, A. (2002). Why Health Equity? Health Economics, $11,659-666$.

Wikler, D. (2003). Why Prioritize when there Isn't Enough Money? Cost Effectiveness and Resource Allocation, $\mathbf{1}, 5$. 